\title{
Hiring Disabled Workers in Times of Coronavirus
}

\section{Silva Neto $\mathrm{MJ}^{*}$}

Deputy General Director of the Brazilian Federal Prosecution Superior School, Brazil

*Corresponding author: Manoel Jorge Silva Neto, General Deputy Attorney, Deputy General Director of the Brazilian Federal Prosecution Superior School, Brazil, Email: manoel.silva@ mpt.mp.br

\section{Opinion}

Norberto Bobbio, a remarkable Italian jurist, in the book "The Age of Rights", stated that "the great problem of human rights today is not so much to justify, but rather to undertake them. It is a political problem, not a philosophical one $^{1}$. Therefore, it is absolutely important to notice that, if there are problems related to the effectiveness of disabled persons' human rights in times of normality, these problems are simply huge in times of coronavirus.

For Instance: Unemployment affects society in general in times of coronavirus, but it affects particularly disabled persons with greater intensity.

In Brazil, article 7, item 31 of the Brazilian Constitution provides special protection for workers with disabilities.

Indeed, article 7, item 31 of the Brazilian Constitution forbids any discrimination in terms of wages and hiring criteria of disabled workers.

On the other hand, Law n. 8.213, of 1991, has forced

1 Review Norberto Bobbio, A Era dos Direitos, Rio de Janeiro: Ed. Campus, 1992, p. 24. companies with more than a hundred of employees to hire people with disabilities.

It is extremely important to create a tolerant atmosphere in the workplace to consolidate a culture of tolerance in everywhere inside and outside the company. By treating disabled workers with dignity and respect, as foreseen in article 1, item 3, of the Brazilian Constitution, hopefully it will also create a healthy cycle of tolerance, which means that if an employee is treated with respect or notice that disabled workers at the treated as the same, there will un-doubtfully exist a repetition of the very same behavior at home.

It seems that fourth generation basic guarantees like affirmative actions are not easy to be respected in times of coronavirus. Yet, difficulty does not mean impossibility. That is why the Brazilian law system has special provisions to enforce human rights of disabled persons.

However, the most effective way to enforce dignity and respect for disabled persons is within the individual.

This is the most difficult task; but the most wonderful one.

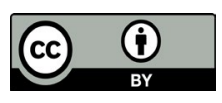

